\title{
Research on Characteristics and Evolution of Female Address Forms in Chinese
}

\section{Sun Guannan}

School of Literature, Baicheng Normal University, Baicheng, Jilin, 137000

\author{
Keywords: Chinese; Female; Address form; Characteristics; Evolution
}

\begin{abstract}
Address form is an important language phenomenon, and it has been the focus of social research for linguistics and modern Chinese. It also has close relationship with social culture, economic status, national culture and national attitude. Female address form is an even more special linguistic phenomenon, and the choice of female address form fully represents various social phenomena in human communication, such as "power", "status" and "equity relationship". From investigation on this special phenomenon, female status and values as well as the social relationship among women and between women and men can be understood. In this paper, a discussion on the characteristics and evolution of Chinese female address form is conducted in combination with traditional Chinese culture and customs.
\end{abstract}

\section{Characteristics of Chinese female address form}

Because of different customs, religious beliefs and values in different countries and regions, choices of female address form are also different. Chinese female address form has the following characteristics because of influences from Chinese people's attention to genetic relationship and the thought that "man is superior to woman":

\subsection{Complication of Chinese nine-generation system and female address form}

Chinese nine-generation system is an important constitution of traditional Chinese culture, and it has complicated variation relationship with female address form. Nine-generation is the general appellation for people with close genetic relationship in traditional Chinese culture. With changes of Chinese dynasties and culture, the implication of nine-generation system is also different in different dynasties and historical periods.

"Nine-generation system" has various versions for a long time, but the following two are the most common:

Firstly, it starts with oneself, and it goes to great-great-grandfather to the top and to great-great-grandson to the bottom. That is to say, starting with oneself, it goes to father, grandfather, great-grandfather and great-great-grandfather to the top; starting with oneself, it goes to son, grandson, great-grandson and great-great-grandson to the bottom, and there are nine generations all together. Secondly, it refers to heterosexual kinship, which means four generations in father's home, three generations in mother's home and two generations in wife's home.

In Chinese nine-generation system, kinship terms for ancient women are abundant. In Erya-Shiqin, there are kinship terms in Zhou Dynasty, "Father is kao, and mother is bi". It means that father is called kao, and mother is called bi. "Great grandfather's bi is called great great-grandmother". (Great grandfather's mother is called great great-grandmother). "Father's shimu and shumu are called zuzumu." (Father's bomu and shumu are called zuzumu.) "As for girls, the first born is elder sister, while the later born is young sister". ("When man meets woman, he calls the first born as elder sister, while the later born as young sister.") "Father's sisters are aunts." "Grandfather's sisters are called wang aunts. Great grandfather's sisters are called great want aunts. Great great grandfather's sisters are called Great great want aunts. Father's grandfather's sisters are called cong grand aunts. Father's great grandfather's sisters are called zu great grand aunts. Father's grandfather's brother's mother is called cong grandmother. Father's great grandfather's brother's mother is called zu great grandmother." "Father's elder brother's wife is called shi mother; father's younger brother's wife is called shu mother. Father's grandfather's brother's wife is called cong 
grandmother, while father's great grandfather's brother's wife is called zu grandmother." "Woman call her husband's father as uncle and her husband's mother as aunt. If uncle and aunt are still alive, they are called jun uncle and jun aunt; if they have passed away, they are called xian uncle and xian aunt. She should call her husband's step-mother as xian aunt, and her husband's elder brother as xionggong, young brother as shu, elder sister nvgong, young sister as nvmei. Son's wife as fu, his legitimate wife as difu, while the concubinage as shufu."

In addition, there is the Chinese character of "yin" in front of many words. For example, "yinweng" is father by marriage, "yinbo" is brother's father-in-law, sister's father-in-law and distant relative's senior. These affinity words are all to show intimacy, and the complication of family members complicates female address forms in ancient words.

\subsection{The phenomenon of "man first " in female address form}

In ancient Chinese people's views, there are hierarchies, affinity, man and woman and inside and outside. These views are fully represented in appellations. Therefore, the phenomenon of "man in front of woman" appears in Chinese female address form, which is the direct reflection of the phenomenon that "man is superior to woman" in traditional Chinese culture. In almost all the words in which there are man and woman, man is at the front, and woman is at the back. For example, kaobi, father and mother, father-in-law and mother-in-law, husband and wife, son and daughter, etc.

In Erya, it is said that "father's kao is called wang father, father's bi is called wang mother." "Wang" means "big" and "respectable". "Grand means respectable father." In traditional Chinese values, it is believed that people have common ancestors, i.e., people having the same family name are respectable. Therefore, grandfather is called "wang father". Correspondingly, "Mother's kao is called outside wang father, and mother's bi is called outside wang mother." "Wife's father is outside uncle, and wife's mother is outside aunt." "Uncle" and "aunt" are wife's parents, and "outside" refers to outside families. In paternal society, mother's parents and wife's parents are all outside families. Therefore, there is the character "outside" for differentiation. In addition, "daughter's children are outside grandchildren." This is also the reflection of "man in front of woman" in traditional Chinese society. It was believed that son belongs to his own family, while daughter is other's family's. Therefore, there is the character "outside" for differentiation of inside and outside.

In Five Virtues of ancient China, it is pointed out clearly that "Wife must submit to her husband", and "When a woman's husband dies, she must submit to her son." Therefore, there are many appellations for woman to submit to husband and son, and this phenomenon still lasts till today. For example, wife follows her husband's to call relatives "his eldest uncle", "his second uncle", etc.

Up to now, there are still many Chinese words in which "man in front of woman" appears, and it has become a fixed language habit. For example, men and women, a man and a woman, a man marries a woman, etc.

\section{Evolution of Chinese female address form}

Language is a social phenomenon and it changes with the development of time. Many elements, such as politics, economy, culture, etc. would all influence the evolution of address forms. Changes of female address form reflect changes of women's status and values, and these changes are determined by women's changes in social production practice.

\subsection{Simplification of kinship terms}

Kinship terms have a strict system in Chinese. It has relative stability and reflects a nation's social culture and cultural traditions.

In ancient China, mother has been called "niang" or "muqin". It is until modern times that it is simplified to "mama'.

Address forms of women's relatives also have changed a lot. For example, in ancient times, mother's parents are called "waigong" and "waipo". With social development in modern times, they are called "laolao" and "laoye". Mother's elder sister was called "yi'niang" in ancient times, and in modern Chinese, it is simplified to "yi". Address forms of relatives were complicated in ancient 
times, and they become simplified with social development, and many of them can be substituted by one or two words.

In Erya-Shiqin, there are 42 kinship terms, which reflect the complexity of social family structure and family members in ancient China. However, with social development, great changes happen to Chinese family structure. According to Feng Hanji's researches, there are over 20 words in modern Chinese that can be called core kinship terms, and they are: zu, sun, zi, mu, xiong, di, zimei, bo, shu, zhi, sheng, gu, jiu, yi, yue, xu, fu, qi, sao, fu, etc. Ancient people regard a big family as honor, and the division of a family as shame. However, small families are more common in modern times, and four generations or five generations are very rare. Therefore, kinship terms are simplified.

\subsection{Complexity of social address forms}

Compared with kinship terms, social address forms have more distinct relevance and class nature. They develop rapidly and have more universality and general significance. China is a country with complicated cultural system, while address forms are restricted by different elements, such as kinship, blood relationship, social status and so on. Therefore, complexity of social address forms comes into being.

\subsubsection{Distinguishing status with social address forms}

Because of influences from traditional Chinese culture, there had been the ideas of "respect for seniority and distinguish noble and lowly". Some positions in Chinese can be used as address forms. Especially when lower level meets higher level, they should call their positions to show respect, such as "chairman, division chief and township head" etc. However, higher level can call lower level "senior (junior) + surname", which is generally acceptable.

\subsubsection{Social address forms distinguish age and social status}

There is not only the custom of "respect for seniority" in Chinese, but also "difference between the inside the outside", and they cannot be mixed up. There is also the habit of "respecting the aged and taking good care of children" in Chinese culture, and it is represented in social address forms. Age represents social status, and "senior" and "junior" is the specific representation, such as "Senior Zhang, Junior Li".

\subsubsection{Difference of positions in social address forms}

Chinese culture is profound, and positions can also be used as address forms. However, not all positions can be used as address forms. Some positions can be used as address forms, such as "doctor, nurse, teacher, professor, engineer". With surnames at the front, these positions can be used as address forms.

\subsection{Transfer, shrinking and extension of the intension of address forms}

From the perspective of social linguistics, address form has profound social intension. China is a country with long-standing history, and the evolution of the development of address forms has its unique intension. Because of influences from social structure, traditional ethics, religious society and many other elements, the intension of female address forms has also extended, shrunk and transferred.

\subsubsection{The extension of address forms}

"Yi": in ancient times, it means wife's or mother's sisters. In modern times, it is extended to senior females beyond kinship. A woman can be called "yi" no matter how old she is. Some children call daycare workers "yi". In many families, babysitters are also called "a'yi". Therefore, "yi" has been extended.

"Xiaojie": the word "Xiaojie" is applied extensively. In ancient China, it means young girls that have not been married. In modern times, the word has developed. At present, the application of the word is even extensive. Some young women who are already married can still be called "Xiaojie". 
However, with the development of modern society, tertiary industry like service industry has also developed. Many waiters in service industry can also be called "Xiaojie". For example, "sale-building xiaojie" at house selling office, etc. Waiters in service industry have been listed in the rank of "Xiaojie". With the development of modern society, "Xiaojie" has also had many subtle implications. Waiters in some high-rank places are also called "Xiaojie". Therefore, it is clear that "Xiaojie" has extended.

\subsubsection{Shrinking of address forms}

The word "gugu" meant husband's mother and father's sisters in ancient times, i.e., mother-in-law. However, it is not the case in modern times. The intension of the word has shrunk. At present, it means father's sisters.

\subsubsection{Transfer of address forms}

"Shuji" (secretary) originally meant people handling documents and writing words. At present, it meant people in charge in various levels of organizations of a party or regiment, and the intension of the word has transferred. There is also the word "Airen (lover)". In ancient Mengzi-Renzhe, it means loving common people. At present, it means the people one loves implicitly. Later, it specifically refers to a man or a woman in love. In modern times, it is the address form of a husband for his wife. Therefore, the meaning of the word has transferred.

\subsection{The disappearance of part of the female address form}

With the development of modern social system and the prohibition of imperialization, many of the address forms for royal families have also disappeared. For example, words like "Huanghou" (queen), "shufei" (princess consort) do not exist anymore in modern society. For example, daughters of ancient leaders were called "gongzhu", "gege" and "junzhu". However, those of modern leaders are just called daughters, and there have not been words like "gongzhu", "gege" anymore. There are also no words like "wangfei" any more.

Because of the implementation of monogamy, the word "yiniang" for "concubinage" are not in use anymore, but it is still used to call mother's sister in the dialects of Shaanxi Province.

In modern society, man and woman enjoy equal status, and many insulting female address forms have also disappeared. For example, ancient men used to call their wives "zaokang" (poor men's foodstuffs) and "jiannei" (my wife), but these words are not existing in modern society. Also, ancient women used to call themselves "jianqie, nubi" modestly, and these words against human dignity also do not exist.

Female address forms tend to become socialized with the improvement of women's social status, and the rise of women's status have also promoted changes of female language. In the past, man was superior to man, but not they are equal. In the past, women used humble language to belittle themselves, but they praise themselves at present. The rise of women's status has promoted unprecedented development of female address forms. It has played more comprehensive role to Chinese linguistics and has become another important subject for linguistic researches.

\section{References}

[1] Zhou Zumo. Erya [M]. Jiangsu: Jiangsu Education Press, 1984.

[2] Cao Wei. Address Forms in Modern Chinese [M]. Beijing: People's Publishing House, 2003.

[3] Hao Yuanyuan. Exploration of the Absence of Current Female Address Form [J]. Journal of Sichuan College of Education, 2005, (11) 